\title{
Celulite em frangos de corte abatidos sob inspeção sanitária: aspectos anatomopatológicos associados ao isolamento de Escherichia coli
}

\section{Cellulitis in broilers slaughtered under sanitary inspection: gross and histopathological lesions associated with isolation of Escherichia coli}

Thaís Badini Vieira, ${ }^{*}$ Robson Maia Franco, ${ }^{* *}$ Helena Magalhães, ${ }^{* * *}$ Carla Inês Soares Praxedes, ${ }^{*}$ Rogério Tortelly, ${ }^{* \star * *}$

\begin{abstract}
Resumo
Objetivou-se descrever lesões macroscópicas e microscópicas consideradas típicas da celulite e sua associação com a presença de E.coli. Para esta pesquisa utilizaram-se 20 frangos de corte. Foram colhidas amostras de pele de dez carcaças com suspeita de celulite e dez sem alterações macroscópicas, constituindo o grupo controle. As amostras de pele das dez aves com suspeitas de celulite mostraram úlcera cutânea, sendo que quatro apresentaram espessamento de pele, alterações na coloração tendendo ao amarelo-avermelhado e irregularidade na superfície cutânea. Ao corte observaram-se fluido gelatinoso e placas amarelas destacáveis e em alguns casos acometimento da musculatura adjacente. As lesões suspeitas de celulite foram confirmadas histologicamente através de aspectos microscópicos específicos da lesão, que se caracterizou por placas fibrinosas ricas em restos celulares, envoltas por infiltrado inflamatório rico em heterófilos ou histiócitos e células gigantes multinucleadas. Na análise bacteriológica foi isolada E.coli em $100 \%$ das lesões de celulite. Como a inspeção veterinária realizada nos matadouros é essencialmente macroscópica, a análise histopatológica torna-se uma ferramenta importante para a confirmação do diagnóstico, permitindo uma rápida diferenciação entre as demais lesões cutâneas. Além disso, a análise bacteriológica permite afirmar que estirpes de E.coli estão freqüentemente associadas a lesões de celulite, tornando esta enfermidade ainda mais relevante em termos de saúde pública.
\end{abstract}

Palavras-chave: frangos de corte; celulite; histopatologia; Escherichia coli.

\begin{abstract}
In this study macroscopic and microscopic descriptions were done from lesions considered typical of cellulites and its association with the presence of E.coli. For this research twenty broiler were used. Samples of the skin were taken form ten carcass under suspicion of cellulites and ten without macroscopic alterations, the last ones becoming the control group. The skin samples from the ten ones under suspicion of cellulites showed cutaneous ulceration, being that four carcass showed thickening of the dermis, alterations in the coloration tending to become yellow-red and abnormalities in the skin. Being cut it was observed a jelly fluid and yellow plaques which are outstanding and, in some cases, there is an assault to the adjoining muscles. The suspected lesions of cellulites were histologically confirmed through the specific microscopic aspects of the lesions, which were characterized by fibrinous plaques rich in cellular scraps involved by inflammatory infiltrated rich in heterophiles or histocytes and multinucleated giant cells. The bacteriological analyses showed the presence of E.coli in $100 \%$ of the cellulites lesions. Regarding that sanitary inspection done in the slaughterhouses is essentially by gross lesions, the histopathological analysis is an important tool to confirm the diagnosis, allowing fast differentiation of the other cutaneuos disease. Besides, the bacteriological analyses allow to confirming that strains of E.coli have frequently been associated with lesions of cellulitis, bringing out this disease very relevant in public health.
\end{abstract}

Keywords: Broiler, cellulites, histological, Escherichia coli.

Programa de Pós-graduação em Medicina Veterinária (mestrado), Área de Concentração: Higiene Veterinária e Processamento Tecnológico de Produtos de Origem Animal da Faculdade de Veterinária Universidade Federal Fluminense, Niterói, RJ, Brasil. Email: thais.badini@ig.com.br.

** Departamento de Tecnologia de Alimentos da Universidade Federal Fluminense, Niterói, RJ, Brasil. E-mail: robsonmf@vm.uff.br

*** Pesquisadora da Área de Bacteriologia do Laboratório de Biologia Animal - PESAGRO-RIO. E-mail: helenanit@yahoo.com.br

**** Departamento de Clínica da Universidade Federal Fluminense, Niterói, RJ, Brasil.

Autor para correspondência: Rogério Tortelly. E-mail: rtortel@microlink.com.br. 


\section{Introdução}

A avicultura brasileira desenvolveu-se e modernizou-se rapidamente alcançando níveis elevados de produtividade nos últimos 30 anos, destacando-se por uma trajetória de incremento tecnológico expressivo, alavancada pela destacada articulação entre os diferentes agentes que o compõe (Girotto e Miele, 2006).

Para alcançar a posição de liderança no mercado avícola mundial, o processamento e a inspeção industrial sofreram evoluções com objetivo de adequar os produtos às exigências do mercado. Incluiu-se rígido controle sanitário no abate, processamento, estocagem e expedição a fim de minimizar os riscos de agentes etiológicos transmissíveis por alimentos e de garantir a qualidade do produto (Andrade, 2005).

Ainda segundo Andrade (2005), muitas enfermidades causam prejuízos à indústria avícola, determinando perdas econômicas consideráveis. Em função da produção em larga escala, do tipo de criação e do manejo de frangos de corte, as lesões cutâneas, como a celulite aviária, vêm-se tornando cada vez mais freqüentes, sendo uma das maiores responsáveis por condenações totais e parciais em todo o mundo, com crescentes prejuízos a avicultura.

As aves destinadas ao consumo são julgadas de acordo com a Instrução Normativa (IN) № 210 de 10/11/1998 do Ministério da Agricultura Pecuária e Abastecimento (Brasil, 1998). De acordo com esta IN, qualquer órgão ou partes de carcaça que estiverem afetados por um processo inflamatório, como a celulite, deverá ter condenação parcial e havendo a evidência de caráter sistêmico, carcaça e vísceras, ocorrerão condenações totais.

A lesão de celulite é caracterizada como uma inflamação purulenta, aguda e difusa do tecido subcutâneo profundo que envolve camadas celulares, havendo a formação de placas fibrino-caseosas no subcutâneo (Norton, 1997; Fallavena, 2000; Alves, 2005; Andrade, 2005). Podendo haver extensão para músculos adjacentes que poderão apresentar pequenos pontos hemorrágicos (Silva e Mota, 2003; Alves, 2005; Andrade, 2005).

A lesão localiza-se principalmente nas regiões de abdômen e sobrecoxa, podendo estar presente também em cabeça e pescoço, coxa, dorso, asas (Fallavena, 2000; Fallavena, 2001; Alves, 2005; Andrade, 2005), peito (Andrade, 2005) e região cervical (Brito et al., 2002), sendo freqüentemente unilateral (Messier et al., 1993; Silva e Mota, 2003; Andrade, 2005).

Bielby (1996) descreveu dois tipos de celulite, sendo a celulite branda caracterizada por uma lesão que não atravessa a pele para a camada subcutânea, sendo menor do que um centímetro de diâmetro; enquanto a celulite moderada a severa pode ser definida como uma lesão que envolve tanto a pele quanto o subcutâneo, podendo promover necrose de gordura, miosite, vasculite local ou outros sinais sistêmicos, e se estendem em qualquer direção mais do que um centímetro.

De acordo com Fallavena (2006) o exame histopatológico parece ser a maneira mais adequada de diagnosticar doenças cutâneas, visto que a maioria das doenças da pele causa aumento na espessura e alterações na coloração sendo, portanto, difícil o seu diagnóstico macroscópico.
Microscopicamente há inflamação do subcutâneo formando massa constituída de restos celulares necróticos e bandas de fibrina, circundadas por cápsula de tecido conjuntivo contendo heterófilos, linfócitos e macrófagos, podendo haver formação granulomatosa, e em alguns casos envolvimento do folículo plumoso (Messier et al., 1993; Onderka et al., 1997; Fallavena, 2000; Fallavena, 2001; Alves, 2005; Andrade, 2005).

A formação granulomatosa é caracterizada por uma fina camada de células epitelióides e células gigantes multinucleadas, além de poucas células mononucleares entremeadas com fibroblastos e fibras colágenas, podendo haver focos de bastonetes Gram-negativos envoltas por um acúmulo de exsudato fibrino-caseoso (Messier et al., 1993; Peighambari et al., 1995; Andrade, 2005;). Nota-se moderada hiperqueratose e hiperplasia da epiderme, com áreas de ulceração focal, espessamento da derme associada à neovascularização e congestão dos capilares subcutâneos (Messier et al., 1993; Peighambari et al., 1995; Onderka et al., 1997; Andrade, 2005).

A celulite é uma das mais importantes fontes de condenação de carcaças nos abatedouros, tendo como causa as enfermidades sistêmicas e implicações com a saúde pública (Onderka et al., 1997), visto que a Escherichia coli é o principal microrganismo encontrado nesta patologia (Onderka et al., 1997; Andrade, 2005).

É indispensável que a pele esteja lesada para que bactérias invadam e se multipliquem no hospedeiro (Norton, Macklin e McMurtrey, 1999; Fallavena, 2000; Fallavena, 2001), embora Elfadil et al. (1996) e Allan (1997) relate que apesar de haver a necessidade de lesões de pele para a ocorrência da celulite, este fator não é isoladamente suficiente para a ocorrência da enfermidade.

Peighambari et al. (1995) realizaram estudos a fim de caracterizar $E$. coli isoladas de celulite aviária e concluíram que a E.coli predominante foi a do grupo 078, estando este sorogrupo associado a várias doenças, incluindo infecções invasivas em humanos e animais.

Tem sido relatado que estirpes de E.coli que colonizam o trato intestinal de frangos são capazes de serem transmitidas aos humanos através do contato íntimo, podendo, inclusive, ser isoladas de amostras fecais humanas (Ojeniyi, 1989 apud Messier, 1993). Além disso, a presença de E. coli nas lesões de celulite favorece a contaminação cruzada nas linhas de processamento de frangos quando estas são expostas (Gomis et al., 2001).

De acordo com Ngeleka et al. (1996) e Kumor et al. (1998) embora não se saiba o potencial que as estirpes isoladas de celulite têm de causar doenças em humanos, as habilidades em adquirir fatores de virulência por transferência genética são fatores a serem considerados.

Assim, embora em alguns casos de lesões de celulite a carcaça possa ser condenada parcialmente, preconiza-se a rejeição total, em função do constante isolamento da Escherichia coli em tais alterações e sua importância em nível de saúde pública (Boulianne, 1999).

Neste estudo objetivou-se descrever lesões macroscópicas e microscópicas consideradas típicas da celulite e sua associação com a presença de E.coli. 


\section{Material e métodos}

Para este estudo foram colhidas amostras de pele de 20 (vinte) frangos de corte com idade entre 35 e 40 dias, oriundas de matadouro sob inspeção estadual. Dez carcaças apresentavam lesões sugestivas de celulite e dez carcaças não apresentavam quaisquer lesões macroscópicas em pele, constituindo o grupo controle. Na coleta de amostras para o exame microbiológico utilizou-se bisturi estéril e com auxílio de zaragatoa estéril, o material foi acondicionado em tubo de ensaio contendo meio Cary e Blair, mantido refrigerado e transportado ao Laboratório de Biologia Animal da PESAGRO$\mathrm{RIO}$, área de Bacteriologia, para o isolamento e caracterização microbiana de acordo com as técnicas de Costa e Hofer (1972) e Analytical Profile Index (API ${ }^{\circledR}$ ) (Biomérieux, 1994). Os fragmentos colhidos para realização do exame histopatológicos foram conservados em frascos contendo formol a $10 \%$, identificados e transportados para o Laboratório de Anatomia Patológica da Faculdade de Veterinária da Universidade Federal Fluminense, onde foi realizado o processamento pelas técnicas habituais de inclusão em parafina e coloração pelo método de hematoxilina-eosina, segundo Meyer e Franks (1986).

Para a análise dos resultados, foi utilizada análise estatística descritiva simples que constou de percentuais, gerando gráficos que possibilitaram o estudo comparativo dos resultados obtidos.

\section{Resultados}

As amostras de pele das dez aves com suspeitas de celulite mostraram úlcera cutânea, sendo que quatro apresentaram espessamento de pele, alterações na coloração tendendo ao amarelo-avermelhado e irregularidade na superfície cutânea. As lesões variaram de três a sete centímetros, sempre unilateralmente. Dentre os dez frangos suspeitos colhidos, quatro apresentaram a lesão em abdômen caudo-lateral esquerdo e seis em abdômen caudo-lateral direito. Ao corte notou-se presença de fluido gelatinoso e placas amarelas destacáveis, ora dispersas e difusas no subcutâneo e em outros, firmes, consistentes e restritas. Em alguns casos foi visível o acometimento da musculatura adjacente, pela presença de focos hemorrágicos.

Com leitura em lâmina, foram encontradas alterações microscópicas que confirmam o diagnóstico positivo da celulite. Os dez casos suspeitos apresentaram placas fibrinosas ricas em restos celulares no subcutâneo envoltas ora por infiltrado inflamatório de histiócitos, ora por infiltrado inflamatório de heterófilos, podendo ser notado em alguns casos focos de colônias bacterianas. Em uma lesão foi observada a presença de células gigantes adjacente à placa fibrino-purulenta. O processo freqüentemente ocasionava espessamento e edema da derme, paniculite ora focal ora difusa, infiltrado inflamatório misto perivascular e em musculatura regional, levando por vezes à destruição.

Das dez amostras de pele do grupo controle, em cinco foram observadas dermatite ulcerativa sem lesões características da celulite.

Estirpes de E. coli foram isoladas em $100 \%$ da amostras oriundas de lesões de celulite e em $40 \%$ das amostras obtidas da pele do grupo controle. Destas últimas, 30\% apresentaram, microscopicamente, dermatite ulcerativa.

\section{Discussão}

Neste trabalho assim como descrito por Fallavena (2000); Fallavena (2001), Alves (2005) e Andrade (2005), as lesões ocorreram em abdômen, sendo freqüentemente unilateral, embora Andrade (2005) tenha evidenciado uma lesão atípica de celulite em peito.

Foi caracterizado que seis das dez aves com lesões suspeitas de celulite não apresentaram alteração da coloração ou espessamento da pele, havendo apenas foco de ulceração. Nestes casos pode ser notado que ao corte, havia, no subcutâneo, placas amareladas. Dessa forma, sugere-se que, apesar da ausência de alterações de pele freqüentemente descrita, a celulite pode estar presente. Tais resultados confrontam-se com os obtidos por Messier et al. (1993); Norton (1997); Onderka et al. (1997); Norton, Macklin e McMurtrey (1999); Fallavena (2001); Brito et al. (2002); Alves (2005) e Andrade (2005) que caracterizaram a lesão de celulite como um processo detectado no abate pela descoloração e engrossamento da pele, com inflamação no tecido subcutâneo.

Em alguns casos notaram-se pontos hemorrágicos em musculatura, assim como relatado por Silva e Mota (2003); Alves (2005) e Andrade (2005).

As lesões de celulite observadas nesta pesquisa estão em conformidade com Bielby (1996), podendo ser classificadas como moderada ou severa visto que as alterações acometiam tanto a pele quanto o subcutâneo, promovendo miosite, vaculite local e necrose de gordura, estendendo-se em qualquer direção mais do que um centímetro.

Microscopicamente, na derme, havia a formação de placa constituída de restos celulares necróticos e bandas de fibrina, circundada por tecido conjuntivo contendo infiltrado inflamatório misto de heterófilos, e em alguns casos presença de barreira de histiócitos e focos de colônias bacterianas. Observaram-se, ainda, células gigantes, infiltrado inflamatório misto difuso que se estendia para tecido muscular e adiposo adjacente, além de vasos sanguíneos. Tais alterações estão de acordo com as observadas por Messier et al. (1993); Onderka et al. (1997); Peighambari et al. (1995); Fallavena (2000; 2001); Brito et al. (2002); Alves (2005) e Andrade (2005).

De acordo com Fallavena (2006) a classificação das doenças de pele não se deve basear apenas no exame macroscópico, uma vez que freqüentemente resulta em erros, sendo mais adequado o exame histopatológico. Neste trabalho as lesões macroscópicas observadas foram correspondentes aos achados histopatológicos característicos da celulite, o que possibilitou o correto diagnóstico da doença, dando subsídios para a equipe de inspeção para o correto julgamento e destino das carcaças.

Apesar de não haver evidências de lesões macroscópicas na pele das aves do grupo controle, em cinco aves foram observadas lesões microscópicas como dermatite ulcerativa restrita ou não, com infiltrado inflamatório misto multifocal da derme. Elfadil et al. (1996) e Allan (1997) relataram que embora haja a necessidade de lesões de pele para a ocorrência de celulite, esta não é isoladamente suficiente para determinar a lesão. Contudo, torna-se indispensável que a pele esteja lesada para que as bactérias penetrem, instale-se no hospedeiro e desenvolvam a celulite de acordo com Norton, Macklin e McMurtrey (1999); Fallavena (2000) e Fallavena (2001). Assim, conforme resultados obtidos nesta pesquisa e os descritos 
pelos autores citados, se sugere que os frangos que apresentaram lesões microscópicas em pele poderiam desenvolver lesões de celulite, por estarem susceptíveis à colonização por E.coli, em função da existência da porta de entrada necessária ao início da infecção.

Tendo em vista o relato apresentado, é possível afirmar que as lesões de celulite são caracterizadas por aspectos microscópicos específicos. Além disso, como a inspeção veterinária realizada nos matadouros é essencialmente macroscópica, a análise histopatológica torna-se uma ferramenta importante para a confirmação do diagnóstico, permitindo uma rápida diferenciação entre as demais lesões cutâneas.

\section{Referências}

ALLAN, B. Cellulitis: Its Microbiology. In:22nd ANNULAPOULTRYSERVICE INDUSTRY WORKSHOP, 1997, Alberta. Anais Eletrônicos... Alberta, Canadá, 1997. Disponível em: <http://www.agric.goc.ab.ca/>. Acesso em: 28 de março de 2004.

ALVES, F.M.X. Celulite Associada às Lesões na Bolsa de Fabrício de Frangos de Corte sob Inspeção Sanitária. Niterói, 2005. Dissertação (Mestrado em Higiene veterinária e processamento Tecnológico de produtos de Origem Animal) - Faculdade de Veterinária, Universidade Federal Fluminense, Niterói. 2005.

ANDRADE, C.L. Histopatologia a Identificação da Escherichia coli como agente causal da celulite aviária em frangos de corte. Niterói, 2005. Dissertação (Mestrado em Higiene veterinária e Processamento tecnológico de produtos de origem animal) - Faculdade de Veterinária, Universidade Federal Fluminense, Niterói. 2005.

BIELBY, M. Economic losses in poultry industry duo to cellulites. Lilydale Poultry, Edmonton, Alberta, 1996. Disponível em: <http:// www.agric.gov.ab.ca/ livestock/poultry/psiw/psiw9704.html> Acesso em: 29 de dezembro de 2003.

BIOMÉRIEUX. Sistem API 20E: Catalogue Analytique. 3. ed. France: L'Etoile, 1994. 441 p.

BOULIANNE, M. Cellulitis in broiler chickens. Missed World Poultry, v.15, p. 56-59, 1999.

BRASIL, Normativa ํㅡ닐, de 10 de novembro de 1998. Aprova o Regulamento Técnico da Inspeção Tecnológica e Higiênico Sanitária da Carne de Aves. Diário Oficial da República Federativa do Brasil, Brasília, DF, 1998.

BRITO, B.G. Celulite em frangos de corte causada por Escherichia coli. Semina, Ciências Agrárias, v. 23, n. 1, p. 81-84, jan./jun., 2002. COSTA, G.A.; HOFER, E. Isolamento e Identificação de Enterobacteriaceas. Rio de Janeiro: Instituto Oswaldo Cruz, 1972. 120 p.

ELFADIL, A.A.; VAILLANCOURT; J.P.; MEEK, A.H.; GYLES, C.L.A prospective study of cellulites in broiler chickens in Southern Ontario. Avian Disease, v. 40, p. 677-689, 1996.

FALLAVENA, L.C.B. Enfermidades da Pele e das Penas. In: BERCHIERI JR, A.; MACARI, M. Doença das Aves. Campinas: FACTA, 2000. 205 p. cap. 2, p. 37-47.

FALLAVENA, L.C.B. Lesões cutâneas em frangos de corte. Disponível em: < http://www.fortdodge.com.br/fd/aves/banner-revista/Revista \%20Aves\%202/lesões.
Neste trabalho a E. coli foi isolada em $100 \%$ das amostras de celulite, reforçando os achados de que a espécie bacteriana está freqüentemente presente em lesões de celulite, assim como descrito por Messier et al. (1993); Fallavena (2000); Fallavena (2001); Brito et al. (2002) e Andrade (2005), o que caracteriza a importância da enfermidade em implicações com saúde pública.

Assim, devido aos riscos relativos à saúde pública e doenças transmissíveis por alimentos, torna-se necessária a reavaliação dos critérios de condenação determinados pela IN $n^{0} 210$ de 10/11/1998 (Brasil, 1998) em casos de celulite aviária.

FALLAVENA, L.C.B. Lesões cutâneas em frangos de corte: Causas, Diagnóstico e Controle. In: CONFERÊNCIAAPINCO 2001 DE CIÊNCIAE TECNOLOGIA, 2001. Anais... Apinco, 2001. p. 205-216.

GIROTTO, A.F.; MIELE, M. Estudos da EMBRAPA - Situação atual e tendências para a avicultura de corte nos próximos anos. Disponible em: <http://www.aviculturaindustrial.com.br/site/dinamica.asp?id $=12024 \&$ tipo_tabela=produtos\&categoria=frango_de_corte $>$ Acesso em: 20 de julho de 2006.

GOMIS, S.M.; RIDDELL, C.; POTTER,A.A.;ALLAN, B.J. Phenotypic and genotypic characterization of virulence factors of Escherichia coli isolated from broiler chickens with simultaneous occurrence of cellulitis and other colibacillosis lesions. The Canadian Journal of Veterinary Reserch, v. 65, p.1-6, 2001.

KUMOR, L.W.; OLKOWSKI, A.A.; GOMIS, S.M.;ALLAN, B.J. Cellulitis in broiler chickens: epidemiological Trends, meat hygiene, and possible human health implicatinos. Avian disease, v. 42, p. 285-291, 1998.

MESSIER, S.; QUESSY, S.; ROBINSON, Y.; DEVRIESE, L.A.; HOMMEZ, J.; FAIRBROTHER, J.M. Focal Dermatitis and Cellulitis in Broiler Chickens: Bacteriological and Pathological Findings. Avian Diesease, v. 37, p. 839-844, 1993.

MEYER, D.J.; FRANKS, S.P. Clinical Cytrology Part 1: Management of Tissue Specimes. M.V.P., p. 440-445, 1986.

NGELEKA, M.; KWAGA, J.K.P.;WHITE, D.G;WHITTAM, T.S.; RIDDELL, C.; GOODHOPE, R.; POTTER, A.A.;ALLAN, B. Escherichia colicellulites in broiler chickens: clonal relationship among strains and analysis of virulence-associated factors of isolates from disease birds. Infected Immunology, v. 64, p. 3118-3126, 1996.

NORTON, R.A. Avian Cellulitis. Word's Poultry Science Journal, v. 53, p. 338-349, 1997.

NORTON, R.A.; MACKLIN, K.S.; McMURTREY, B. L. Evaluation of scratches as an essential element in the development of avian cellulitis in broiler chickens. Avian Disease, v. 43, p. 320-325, 1999.

OJENIYI, A.A. Direct transmission of Escherichia coli from poultry to humans. Epidemiol. Infect, v. 103, p. 513-522, 1989.

ONDERKA, D.K.; HANSON, J.A.; McMILLAN, K.R.; ALLAN, B. Escherichia coli Associated Cellulitis in Broilers: Correlation with Systematic Infection and Microscopic Visceral Lesions, and Evalution for Skin Trimming. Avian Disease, v. 41, p. 935-940, 1997.

PEIGHAMBARI, S.M.; JULIAN, R.J.; VAILLANCOURT, J.P.; GYLES, C.L. Escherichia coli cellulitis: Experimental infections in broiler chickens. Avian Disease, v. 39, p. 125-134, 1995.

SILVA, E.N.; MOTA, M.P. Celulite em Frangos de Corte. Disponível em: <http://www.fatec.com.br/trabtec/celulite_em_frangos_de_ corte.htm>. Acesso em: 27 de novembro de $200 \overline{3}$. 